\title{
ANALISIS KESTABILAN MODEL LOTKA-VOLTERRA YANG DIPENGARUHI OLEH FAKTOR IMIGRASI
}

\author{
CHYNTIA DWI YAN, BUDI RUDIANTO \\ Program Studi S1 Matematika, \\ Fakultas Matematika dan Ilmu Pengetahuan Alam, Universitas Andalas, \\ Kampus UNAND Limau Manis Padang, Indonesia. \\ email : chyntiadwiyan4@gmail.com
}

Diterima 9 Maret 2019 Direvisi 7 April $2019 \quad$ Dipublikasikan 7 Mei 2019

\begin{abstract}
Abstrak. Dalam makalah ini dikaji kestabilan model Lotka-Volterra yang dipengaruhi oleh faktor imigrasi.

Kata Kunci: Model Lotka-Volterra, Ketabilan titik tetap, Imigrasi
\end{abstract}

\section{Pendahuluan}

Diberikan model Lotka-Volterra sebagai berikut :

$$
\begin{aligned}
& \frac{d x}{d t}=r x-a x y, \\
& \frac{d y}{d t}=b x y-m y,
\end{aligned}
$$

dimana $x(t)$ adalah populasi mangsa, $y(t)$ adalah populasi pemangsa dan $r, a, b, m$ adalah konstanta positif. Jika terjadi imigrasi pada lingkungan dimana pemangsa dan mangsa berada, maka model (1.1) dapat diubah menjadi:

$$
\begin{aligned}
& \frac{d x}{d t}=r x-a x y+C(x) \\
& \frac{d y}{d t}=b x y-m y+D(y),
\end{aligned}
$$

dimana:

$C(x)=$ Fungsi imigrasi pada populasi mangsa $D(y)=$ Fungsi imigrasi pada populasi pemangsa.

Secara sederhana titik tetap $\left(x_{1}^{*}, x_{2}^{*}\right)$ dari sistem (1.2) untuk $n=2$ dikatakan stabil jika kurva solusi (trayektori) yang berawal dari $\left(x_{01}, x_{02}\right)$, yang pada mulanya dekat dengan titik tetap tersebut, maka dengan berlalunya waktu kurva solusi tersebut senantiasa dekat dengan titik tetap. Suatu titik tetap $\left(x_{1}^{*}, x_{2}^{*}\right)$ dari sistem (1.2) untuk $n=2$ dikatakan stabil asimtotik jika sistem tersebut stabil dan dengan berlalunya waktu, trajektori tersebut semakin dekat(bergerak menuju) ke titik tetap itu $\left(\lim _{t \rightarrow \infty}\left(x_{1}(t), x_{2}(t)\right)=\left(x_{1}^{*}, x_{2}^{*}\right)\right)$. 


\section{Pembahasan}

Beberapa kemungkinan fungsi imigrasi adalah sebagai berikut.

(1) $C(x)=c, c \geq 0$,

(2) $C(x)=\frac{c}{x}, c>0, x \neq 0$,

(3) $D(y)=d, d \geq 0$,

(4) $D(y)=\frac{d}{y}, d>0, y \neq 0$,

dimana

$c=$ jumlah imigran dari populasi mangsa

$d=$ jumlah imigran dari populasi pemangsa

$\frac{c}{x}=$ proporsi imigran dari populasi mangsa

$\frac{d}{y}=$ proporsi imigran dari populasi pemangsa

Dalam makalah ini akan dikaji empat kasus yang mungkin terjadi pada model (1.2), yaitu:

Kasus 1. $C(x)=c, D(y)=0$.

Kasus ini bermakna bahwa ada sebanyak $c$ imigran mangsa dan tidak ada imigran pemangsa, sehingga persamaan (1.2) menjadi :

$$
\begin{aligned}
& \frac{d x}{d t}=r x-a x y+c \\
& \frac{d y}{d t}=b x y-m y .
\end{aligned}
$$

Titik tetap untuk sistem $(2.1)$ adalah $\left(x_{1}^{*}, y_{1}^{*}\right)=\left(-\frac{c}{r}, 0\right)$ dan $\left(x_{2}^{*}, y_{2}^{*}\right)=$ $\left(\frac{m}{b}, \frac{b c+m r}{m a}\right)$.

Nilai eigen dari $J\left(-\frac{c}{r}, 0\right)$ adalah

$$
\lambda_{1}=r \quad \text { dan } \quad \lambda_{2}=-\frac{b c+m r}{r} .
$$

Ingat bahwa $r, c, m, b$ adalah positif, sehingga titip tetap $\left(-\frac{c}{r}, 0\right)$ adalah tidak stabil. Nilai eigen dari $J\left(\frac{m}{b}, \frac{b c+m r}{m a}\right)$ adalah

$$
\lambda_{1,2}=\frac{-\tau \pm \sqrt{\tau^{2}-4 \Delta}}{2}
$$

dengan $\tau=\frac{b c}{m}$ dan $\Delta=m r+b c$.

Kasus 2. $C(x)=0, D(y)=d$.

Kasus ini bermakna bahwa tidak ada imigran mangsa dan ada sebanyak $d$ imigran pemangsa, sehingga persamaan (1.2) menjadi :

$$
\begin{aligned}
& \frac{d x}{d t}=r x-a x y \\
& \frac{d y}{d t}=b x y-m y+d .
\end{aligned}
$$

Titik tetap untuk sistem (2.3) adalah $\left(x_{1}^{*}, y_{1}^{*}\right)=\left(0, \frac{d}{m}\right)$ dan $\left(x_{2}^{*}, y_{2}^{*}\right)=$ $\left(\frac{r m-a d}{r b}, \frac{r}{a}\right)$. 
Nilai eigen dari $J\left(0, \frac{d}{m}\right)$ adalah

$$
\lambda_{1,2}=\frac{-\left(m-r+\frac{a d}{m}\right) \pm \sqrt{\left(m+r-\frac{a d}{m}\right)^{2}}}{2}
$$

dimana $\lambda_{1}=\left(r-\frac{a d}{m}\right)$ dan $\lambda_{2}=-m$.

Jika $\frac{a d}{m}>r$ maka nilai eigen $\lambda_{1}$ dan $\lambda_{2}$ adalah bilangan riil negatif, sehingga titik tetap $\left(0, \frac{d}{m}\right)$ adalah stabil. Jika $\frac{a d}{m}<r$ maka nilai eigen $\lambda_{1}$ dan $\lambda_{2}$ adalah bilangan riil berlawanan tanda, sehingga titik tetap $\left(0, \frac{d}{m}\right)$ adalah tidak stabil.

Nilai eigen dari $J\left(\frac{r m-a d}{b r}, \frac{r}{a}\right)$ adalah

$$
\lambda_{1,2}=\frac{-\tau \pm \sqrt{\tau^{2}-4 \Delta}}{2}
$$

dengan $\tau=\frac{a d}{r}$ dan $\Delta=m r-a d$.

Perhatikan dua sub-kasus berikut.

Kasus 2a. $\left(\tau^{2}-4 \Delta\right)<0$.

Dalam kasus ini nilai eigen $\lambda_{1}$ dan $\lambda_{2}$ adalah bilangan imajiner, sehingga titik tetap $\left(\frac{r m-a d}{b r}, \frac{r}{a}\right)$ stabil jika $\alpha>0$ dan tidak stabil jika $\alpha<0$, dimana $\alpha=\frac{a d}{2 r}$ dan $\beta=\sqrt{\frac{a^{2} d^{2}}{4 r^{2}}-m r+a d}$.

Kasus 2b. $\left(\tau^{2}-4 \Delta\right)>0$.

Dalam kasus ini jika $\tau<\sqrt{\tau^{2}-4 \Delta}$, maka nilai eigen $\lambda_{1}$ dan $\lambda_{2}$ adalah bilangan riil berbeda tanda, sehingga titik tetap $\left(\frac{r m-a d}{b r}, \frac{r}{a}\right)$ adalah tidak stabil. Jika $\tau>\sqrt{\tau^{2}-4 \Delta}$, maka nilai eigen $\lambda_{1}$ dan $\lambda_{2}$ adalah bilangan riil negatif, sehingga titik tetap $\left(\frac{r m-a d}{b r}, \frac{r}{a}\right)$ adalah stabil.

Kasus 3. $C(x)=\frac{c}{x}, D(y)=0$.

Kasus ini bermakna bahwa ada proporsi imigran dari populasi mangsa dan tidak ada imigran dari populasi pemangsa, sehingga persamaan (1.2) menjadi :

$$
\begin{aligned}
& \frac{d x}{d t}=r x-a x y+\frac{c}{x} \\
& \frac{d y}{d t}=b x y-m y .
\end{aligned}
$$

Titik tetap untuk sistem $(2.5)$ adalah $\left(x_{1}^{*}, y_{1}^{*}\right)=\left(\frac{m}{b}, \frac{b^{2} c+m^{2} r}{m^{2} a}\right)$.

Nilai eigen dari $J\left(\frac{m}{b}, \frac{b^{2} c+m^{2} r}{m^{2} a}\right)$ adalah

$$
\lambda_{1,2}=\frac{-\tau \pm \sqrt{\tau^{2}-4 \Delta}}{2}
$$

dengan $\tau=\frac{2 b^{2} c}{m^{2}}$ dan $\Delta=\frac{b^{2} c+m^{2} r}{m}$.

Perhatikan dua sub-asus berikut.

Kasus 3a. $\left(\tau^{2}-4 \Delta\right)<0$.

Dalam kasus ini nilai eigen $\lambda_{1}$ dan $\lambda_{2}$ adalah bilangan imajiner, sehingga titik tetap $\left(\frac{m}{b}, \frac{b^{2} c+m^{2} r}{m^{2} a}\right)$ stabil jika $\alpha>0$ dan tidak stabil jika $\alpha<0$, dimana $\alpha=\frac{b^{2} c}{m^{2}}$ dan $\beta=\sqrt{\frac{b^{4} c^{2}}{m^{4}}-\frac{b^{2} c}{m}-m r}$. 
Kasus 3b. $\left(\tau^{2}-4 \Delta\right)>0$.

Dalam kasus ini jika $\tau<\sqrt{\tau^{2}-4 \Delta}$, maka nilai eigen $\lambda_{1}$ dan $\lambda_{2}$ adalah bilangan riil berbeda tanda, sehingga titik tetap $\left(\frac{m}{b}, \frac{b^{2} c+m^{2} r}{m^{2} a}\right)$ adalah tidak stabil. Jika $\tau>\sqrt{\tau^{2}-4 \Delta}$, maka nilai eigen $\lambda_{1}$ dan $\lambda_{2}$ adalah bilangan riil negatif, sehingga titik tetap $\left(\frac{m}{b}, \frac{b^{2} c+m^{2} r}{m^{2} a}\right)$ adalah stabil.

Kasus 4. $C(x)=0, D(y)=\frac{d}{y}$.

Kasus ini bermakna bahwa tidak ada imigran mangsa dan ada proporsi imigran dari populasi pemangsa, sehingga persamaan (1.2) menjadi :

$$
\begin{gathered}
\frac{d x}{d t}=r x-a x y \\
\frac{d y}{d t}=b x y-m y+\frac{d}{y} .
\end{gathered}
$$

Titik tetap untuk sistem $(2.6)$ adalah $\left(x_{1}^{*}, y_{1}^{*}\right)=\left(0, \pm \sqrt{\frac{d}{m}}\right)$ dan $\left(x_{2}^{*}, y_{2}^{*}\right)=$ $\left(\frac{r^{2} m-a^{2} d}{r^{2} b}, \frac{r}{a}\right)$.

Nilai eigen dari $J\left(0, \sqrt{\frac{d}{m}}\right)$ adalah

$$
\lambda_{1}=r-a \sqrt{\frac{d}{m}} \quad \lambda_{2}=-2 m
$$

Jika $a \sqrt{\frac{d}{m}}>r$ maka nilai eigen $\lambda_{1}$ dan $\lambda_{2}$ adalah bilangan riil negatif, sehingga titik tetap $\left(0, \sqrt{\frac{d}{m}}\right)$ adalah stabil. Jika $a \sqrt{\frac{d}{m}}<r$ maka nilai eigen $\lambda_{1}$ dan $\lambda_{2}$ adalah bilangan riil berlawanan tanda, sehingga titik tetap $\left(0, \sqrt{\frac{d}{m}}\right)$ adalah tidak stabil.

Nilai eigen dari $J\left(0,-\sqrt{\frac{d}{m}}\right)$ adalah

$$
\lambda_{1}=r+a \sqrt{\frac{d}{m}} \quad \lambda_{2}=-2 m
$$

Ingat bahwa $r, a, d, m$ adalah positif, maka diperoleh $\lambda_{1}$ dan $\lambda_{2}$ adalah bilangan riil yang berlawanan tanda, sehingga titip tetap $\left(0,-\sqrt{\frac{d}{m}}\right)$ adalah tidak stabil.

Nilai eigen dari $J\left(\frac{r^{2} m-a^{2} d}{r^{2} b}, \frac{r}{a}\right)$ adalah

$$
\lambda_{1,2}=\frac{-\tau \pm \sqrt{\tau^{2}-4 \Delta}}{2}
$$

dengan $\tau=\frac{2 a^{2} d}{r^{2}}$ dan $\Delta=\frac{m r^{2}-a^{2} d}{r}$.

Perhatikan dua kasus berikut.

Kasus 4a. $\left(\tau^{2}-4 \Delta\right)<0$.

Dalam kasus ini nilai eigen $\lambda_{1}$ dan $\lambda_{2}$ adalah bilangan imajiner, sehingga titik tetap 
$\left(\frac{r^{2} m-a^{2} d}{r^{2} b}, \frac{r}{a}\right)$ stabil jika $\alpha>0$ dan tidak stabil jika $\alpha<0$, dimana $\alpha=\frac{a^{2} d}{r^{2}}$ dan $\beta=\sqrt{\frac{-a^{4} d^{2}}{r^{4}}-m r-\frac{a^{2} d}{r}}$.

Kasus 4b. $\left(\tau^{2}-4 \Delta\right)>0$.

Dalam kasus ini jika $\tau<\sqrt{\tau^{2}-4 \Delta}$, maka nilai eigen $\lambda_{1}$ dan $\lambda_{2}$ adalah bilangan riil berbeda tanda, sehingga titik tetap $\left(\frac{r^{2} m-a^{2} d}{r^{2} b}, \frac{r}{a}\right)$ adalah tidak stabil. Jika $\tau>$ $\sqrt{\tau^{2}-4 \Delta}$, maka nilai eigen $\lambda_{1}$ dan $\lambda_{2}$ adalah bilangan riil negatif, sehingga titik tetap $\left(\frac{r^{2} m-a^{2} d}{r^{2} b}, \frac{r}{a}\right)$ adalah stabil.

Berikut adalah gambar potret fase untuk keempat kasus diatas, dengan $x(0)=$ $5, y(0)=5, r=0.1, a=0.1, b=0.3, m=0.2, c=0.01, d=0.01$ dimana $\left(\tau^{2}-4 \Delta\right)<$ 0 .

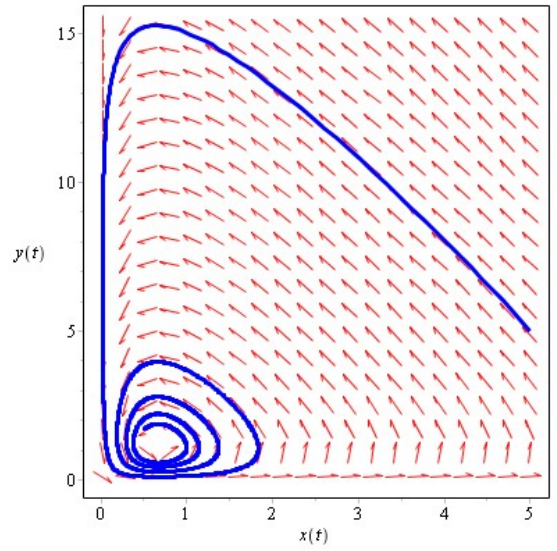

Gambar 3.5.1: $C(x)=c, D(y)=0$

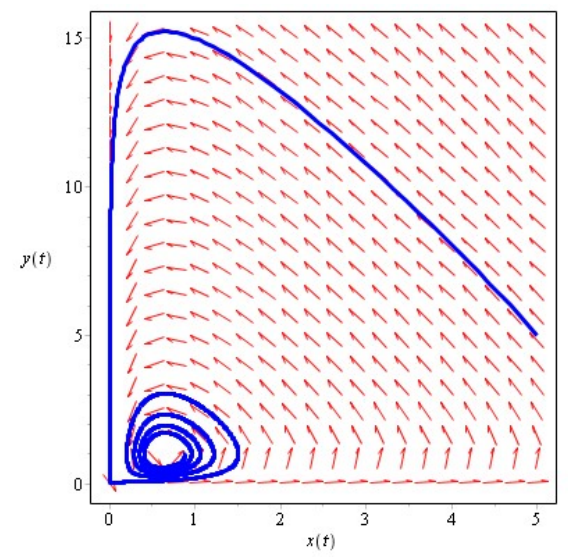

Gambar 3.5.3: $C(x)=0, D(y)=d$

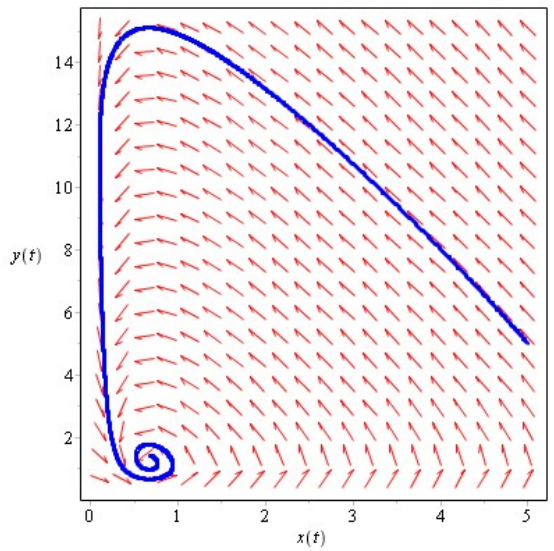

Gambar 3.5.2: $C(x)=c / x, D(y)=0$

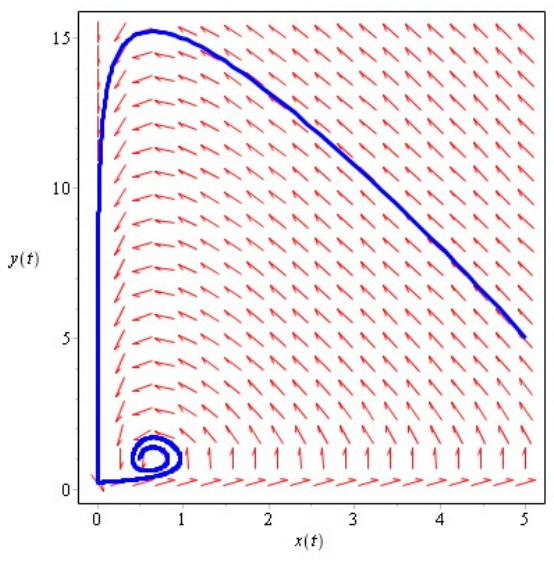

Gambar 3.5.4: $C(x)=0, D(y)=d / y$ 


\section{Kesimpulan}

Telah dilakukan analisis terhadap (1.2), model tersebut memuat faktor imigrasi. Dalam model (1.2) terdapat empat kasus yang mungkin terjadi, yaitu:

(1) $C(x)=c, D(y)=0$,

(2) $C(x)=0, D(y)=d$,

(3) $C(x)=\frac{c}{x}, D(y)=0$,

(4) $C(x)=0, D(y)=\frac{d}{y}$.

Dari keempat kasus tersebut didapatkan delapan titik tetap, dengan perincian sebagai berikut.

(1) Untuk $C(x)=c, D(y)=0$, titik tetap $\left(-\frac{c}{r}, 0\right)$ tidak stabil dan titik tetap $\left(\frac{m}{b}, \frac{b c+m r}{m a}\right)$ stabil.

(2) Untuk $C(x)=0, D(y)=d$, titik tetap $\left(0, \frac{d}{m}\right)$ dan $\left(\frac{r m-a d}{b r}, \frac{r}{a}\right)$ stabil.

(3) Untuk $C(x)=\frac{c}{x}, D(y)=0$, titik tetap $\left(\frac{m}{b}, \frac{b^{2} c+m^{2} r}{m^{2} a}\right)$ stabil.

(4) Untuk $C(x)=0, D(y)=\frac{d}{y}$.titik tetap $\left(0, \sqrt{\frac{d}{m}}\right)$ dan $\left(\frac{r^{2} m-a^{2} d}{r^{2} b}, \frac{r}{a}\right)$ stabil, titik tetap $\left(0,-\sqrt{\frac{d}{m}}\right)$ tidak stabil.

\section{Ucapan Terima kasih}

Penulis mengucapkan terima kasih kepada bapak Dr. Mahdhivan Syafwan, bapak Dr. Admi Nazra, ibu Dr. Susila Bahri selaku dosen penguji yang telah memberikan masukan dan saran sehingga makalah ini dapat diselesaikan dengan baik.

\section{Daftar Pustaka}

[1] Anton, H. 2005. Elementary Linier Algebra. Ninth Edition. John Willey. New York.

[2] Boyce,W.E. and Diprima,R.C. 1999. Ordinary Differential Equations and Boundary Value Problems. $5^{\text {th }}$ Edition. John Wiley dan Sons, Inc. Canada

[3] Hendricks. Elbert, Ole. Jannerup dan P. H. Sorensen. 2008. Linear Systems Control. Springer- Verlag Berlin Heidelberg

[4] Lynch, Stephen. 2007. Dynamical Systems with Applications using Mathe- matics. Birkhäuser Boston, Cambridge.

[5] Redjeki, P.S. 2009. Diktat Kuliah MA2271 Metoda Matematika. Bandung: Fakultas MIPA ITB.

[6] Tahara, T., Gavina, M.K.A., Kawano, T., Tubay, J.M., Rabajante, J.F., Ito, H., Morita, S., Ichinose, G., Okabe, T., Togashi, T., Tainaka, K., Shimizu, A., Nagatani, T., and Yoshimura, J. 2018 . Asymptotic Stability Of a Modified LotkaVolterra Model With Small Immigrations, Scientific Reports, 8:7029, hal. 1 - 7. 